\title{
Priorities for the sustainable development of inland capture fishery
}

\author{
Anna Shishigina ${ }^{1, *}$, Vladimir $\operatorname{Sosin}^{1}$ \\ ${ }^{1}$ North and Arctic Interdisciplinary Research Division of Arctic Scientific Research Centre, Academy of Sciences of Sakha Republic, 22 \\ Kurashova st., Yakutsk, 677000, Russia
}

\begin{abstract}
Fishing in inland waters significantly differs in terms of production, seasonality, scale, methods of production and organization of fishing, equipment and technologies. In addition, fishing in inland waters is characterized by insignificant volumes of catch of aquatic bioresources and other socio-economic significance. As a rule, this type of activity is occupied by small organizations that use seasonal labor with temporary employment, which, at the same time, are of significant socio-economic importance for the local population. The article presents the characteristics of the situation in the field of industrial fishing in the Sakha Republic (Yakutia) and the main problematic trends of the industry. The purpose of the article is to show the main obstacles to the sustainable development of inland fisheries in the Sakha Republic (Yakutia) in fresh waters. As a result of the study, measures are proposed to solve the problems. The management should be focused on the rationalization of fishing to increase profits per unit of production assets used, as well as on attracting highly qualified specialists to fishing, that is, increasing the investment attractiveness of this industry. With this approach, inland fisheries can contribute substantially to increased food security, poverty alleviation, livelihoods, human well-being and ecosystem function.
\end{abstract}

\section{Introduction}

Managing the sustainable development of fisheries is an international challenge. In 1988, FAO agreed on the definition of sustainable development given by the World Commission on Environment and Development (1987) - "development that meets the needs of the present generation without compromising the ability of future generations to meet their own needs". All things considered that the management for the sustainable development of industrial fisheries has the object of the conservation and rational use of biological resources. That is enabling conditions when the reproduction of exploited populations remains at the highest possible level and produces maximum high-quality products with the minimum possible expenditure of effort and resources while preserving a balanced exploitation of stocks.

Inland fisheries in Yakutia is the only traditional economic activity in the North that produces real industrial products. Fish is not only the most important biotic resource for the population in the Arctic, but also a source of income and plays an important role in the social structure of the local population. At the same time, in Russia, the management of inland fisheries in freshwater is limited to the approved total allowable catch and the volume of possible catch of aquatic bioresources including a ban to fishing in the regions of the Russian Federation. But, as world practice has shown, inland fisheries have never been included in any major global fisheries assessment and, in particular, have not been included in the Sustainable Development Goals, their life support component is underestimated and largely ignored [10, 12]. This is related to the landing size. Global catches in inland waters are for 12.5 per cent of total fishing production. This capture varies wildly among the top catch producers, accounting for less than 1 per cent of total catches in the United States, Japan and Peru, compared to 44 per cent and 65 per cent of total catches in Myanmar and Bangladesh respectively. Inland fisheries are also important for food security in Africa, which accounts up to 25 percent of global inland fisheries, when combined catches in Europe and the Americas are about 9 percent [1].

It would be hard to overestimate the importance of inland fisheries for the food security of the Arctic peoples. The livelihoods of the Arctic peoples in Yakutia are becoming increasingly vulnerable due to recent changes in climatic and environmental conditions, alongside with the political and economic transformations [11].

\section{Results and Discussion}

Despite the relatively small size of the production of aquatic bioresources in the Sakha Republic (Yakutia), the life of the population of the Arctic region of the Sakha Republic (Yakutia), including the indigenous peoples of the North, critically depends on the functioning of the fishing industry.

Corresponding author: schanan@yandex.ru 
The analysis of fish catch on the main rivers for the specified period shows that the main share of industrial fish is caught in the basins of 4 main fishing rivers, in which $25,086.6$ tons or $94.8 \%$ of the total volume were caught, including:

- Lena River $-40.1 \%$ or $10,676.6$ tons,

- Kolyma River $-19.2 \%$ or $5,111.4$ tons,

- Yana River $-18.4 \%$ or 8,886 . 7 tons,

- Indigirka River $-16.6 \%$ or $4,411.9$ tons.

As of January 1, 2020, in the Sakha Republic (Yakutia), a total of 952 fishing areas were formed, including 471 river and 481 lake areas. In view of the latest legislative changes, the situation with ensuring public access to the use of aquatic biological resources has improved. Nevertheless, in prospect it is necessary to optimize the regulations on the formation of fishing areas with the exception of all inconsistencies of various federal and republican departments, to provide open access to the List of fishing areas of the Sakha Republic (Yakutia) via the Internet, to facilitate and speed up the procedures for holding competitive tenders for fishing areas consolidation.

The implementation rate of allocated quotas on lakes is much lower than on rivers $(59.5 \%$ against $77 \%$ of river ones) due to its assortment consisting of less valuable fish, such as perch, roach, char, minnow and others. At the same time, one of the main reasons for the partial implementation of quotas is also the extreme remoteness of the lake areas, which requires high costs for transporting the fish from the sites to the receiving points. For this reason alone, in the basins of the Khrom and Alazeya rivers more than 700 tons of quotas have not been reached, including chir and ryapushka (Table $1)$.

Table 1. Dynamics of the catch of aquatic bioresources and the development of allocated quotas for 2015-2019

\begin{tabular}{|c|c|c|c|}
\hline Years & $\begin{array}{c}\text { Allocated } \\
\text { quotas, tons }\end{array}$ & $\begin{array}{c}\text { Actual } \\
\text { catch, tons }\end{array}$ & $\begin{array}{c}\text { percent of } \\
\text { development }\end{array}$ \\
\hline 2015 & 6848.30 & 4704.96 & 68.7 \\
\hline 2016 & 7265.52 & 4921.34 & 67.7 \\
\hline 2017 & 7502.79 & 5474.77 & 73 \\
\hline 2018 & 7932.16 & 5757.5 & 72.6 \\
\hline 2019 & 7706.41 & 5718.74 & 74.2 \\
\hline Total & $\mathbf{3 7 2 5 5 . 1 8}$ & $\mathbf{2 6 5 7 7 . 3 1}$ & $\mathbf{7 1 . 3}$ \\
\hline
\end{tabular}

Industrial fish catch sizes for the period of 2015-2020 in the Republic are about 26,577. 31 tons with the fishing quotas of 37,255. 18 tons. The average annual catch of fish is 5,315. 5 tons. Over the last years, the volume of catch of burbot and pike has increased, which is probably due to the introduction of technologies for their processing and the growing demand for these products. If the catch of burbot and pike in 2014 amounted to 75 and 184 tons per year, then in 2019 they were already 205 and 386 tons respectively. Also the percentage of the implementation of quotas for these fish species has also increased. The question is raised by the very low implementation percentage of quotas for catching carp, which is less than $50 \%$ annually. Even in the Kobyai ulus, the quotas implementation percentage for catching carp is only $43 \%$.

The main share of industrial fish catch is provided by seven fishing areas that are part of the Arctic zone: Bulunsky, Ust-Yansky, Allaikhovsky, NizhneKolymsky, Zhigansky, Sredne-Kolymsky and Abysky uluses, which produce the lion's share $(88.1 \%)$ of the total volume of extracted fish. The largest fishing farms in the Republic are Artel (fishing collective farm) "Arctic", Municipal unitary enterprise "Bulunskoye" from Bulunsky, PC KRO "Russian Ustye", PC KRO "Allaikha" from Allaikhovsky, PC KRO "Turvaurgin", SPK KMNS "Pokhodsky", KRO KMNS-Yukagirov "Chobul" from Nizhnekolymsky, SPK KRO Ilin-Shar, LLC Ust-Yansky and other medium-sized farms from Ust-Yansky.Yansky ulus. These fishing farms are economic bases in their locations and the socioeconomic situation of such settlements as Bykovsky, Kyusyur, Taimylyr, Russian Ustye, Pokhodsky, Kolymskoye, Andryushkino, Kazachye, Ust-Yana, etc. depends on the results of their economic activity.

The analysis of the catch structure of aquatic biological resources by the organizations of all forms of ownership shows that more than half $(55 \%)$ of these aquatic biological recourses are fished by production cooperatives (25 large and medium-sized farms), 30\% are fished by individual entrepreneurs and LLC, and indigenous communities of small-numbered peoples of the North account for no more than $5 \%$ of the total catch (Figure 1).

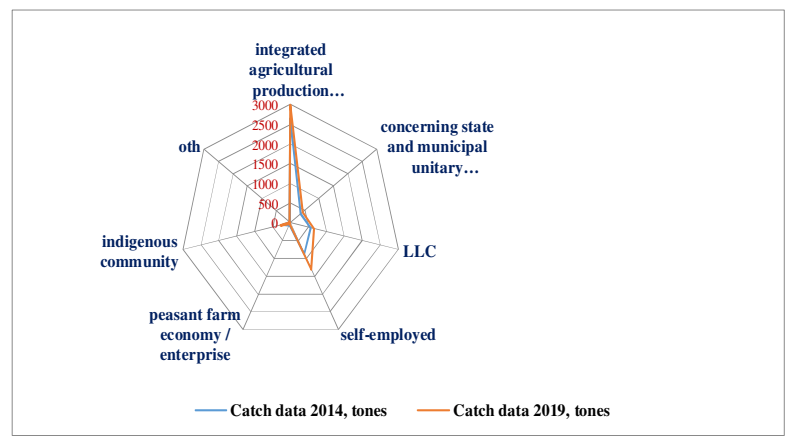

Figure 1. Catch data of organizations for 2014 and 2019.

At the same time, there is an increase of small farms in the industry, which is an undesirable factor. In today's market conditions the introduction of modern fishing technologies, freezing, storage and transportation of fish in order to preserve the high quality fish produced requires large financial investments for the purchase of appropriate equipment, equipment and fleet, which is beyond the power of small farms and individual entrepreneurs.

Fishing in the conditions of the Far North is a complex production process that carries large financial costs for its organization, and these costs occur before income is received, that is, before the period of fish production in connection with the preparations for the harvest - this is the purchase of fish, other materials, products, their delivery to the fish sites by the winter road, the input requirements should be met before 
harvesting products. Thus a huge cash gap is generated, which in previous years was partially covered by advancing state subsidies for industrial fishing. This made it possible to carry out a successful summer fishing season, of course, taking into account the natural and hydrological conditions. But starting in 2018, this type of state subsidy is given only to small and medium-sized fishing farms with quotas of up to 50-70 tons.

Fish in the Republic is mainly sold unprocessed through all sales channels via small enterprises (66\%), peasant farms and individual entrepreneurs (19.7\%), large and medium-sized organizations (13.4\%). On average in the domestic market of the Republic $1300-1$ 600 tons of fresh-frozen fish is purchased for processing per year.

Despite the fact that the Republic cannot export large volumes of products outside the territory of Yakutia, as there is a dependence on imports and a weak level of food self-sufficiency, the Yakut fish is supplied to the Amur, Tyumen, Kemerovo, Novosibirsk, Moscow and Leningrad regions, Altai and Primorsky Territories, as well as to Moscow. According to the Far Eastern Customs Administration, the export of Yakut fish is carried out to the People's Republic of China, the volume of which amounted to 10.9 tons in 2019. According to the report of the Federal Customs Service, in 2019, the export of fish products from the Sakha Republic (Yakutia) amounted to 60.3 thousand US dollars in monetary terms.

About $90 \%$ of especially valuable fish species, such as sturgeon, nelma and taimen, are sold mainly by direct deliveries, and in recent years the volume of omul, chir and muksun supplied by direct deliveries has also been growing, with fish often being shipped outside the Republic.

At the same time, according to the federal statistical observation (excluding microenterprises and individual entrepreneurs), in the Sakha Republic (Yakutia) since 2014, there has been almost four-time increase in the import of fish products and in 2018 it amounted to 144.1 tons. While the export of $1500-2000$ tons of freshfrozen fish outside the Republic per year, the share of imported fish products is growing, there is clearly a dependence on imports and a weak level of food selfsufficiency for the residents of the Republic. Some authors [2] attribute this to the deficiency of opportunities for the majority of fish processing enterprises to produce high-quality and competitive products that meet the requirements of world standards (the capabilities of fish processing organizations in Yakutsk are severely limited due to lack of working capital, the small capacity of the Yakutsk market, and the low purchasing power of the population). This fact is contrary to the general trend of the Russian Federation, which is characterized by a significant change in the size and co-relation of export and import operations in terms of fish and fish products with a steady trend of reducing the latter [3].

In recent years, there have been situations when every second fishing enterprise has been operating on the verge of loss. According to the Federal State Statistics Service in the Sakha Republic (Yakutia) in 2016 and
2018, the share of unprofitable organizations in the total number of organizations by the type of economic activity "fishing" was 50\% and 53.8\%, respectively.

The fisheries sector of the Sakha Republic (Yakutia) is currently in a state of crisis and is facing a whole range of different problems related to the influence of such well-known and characteristic factors for the Arctic region as the deficiency of territorial connectivity, long distances, extreme climate, etc. However problems that directly depend on the effectiveness of the state policy in the field of fisheries. There are the underdevelopment of the basic fishing infrastructure, the obsolescence of the material and technical base of fishing farms, a significant increase in the number of small enterprises, and an acute shortage of qualified personnel, have no less impact on the state of the fisheries complex.

Planning and forecasting are among the most important functions of public administration in the fisheries sector. At the same time, at the current stage of development, such work actually consists in making forecasts of the biological productivity of fishing areas by industry institutions, as well as developing industry strategies and programs initiated by the Federal Agency for Fisheries and the regional government, which is clearly not enough.

Considering these problems in order to find ways to solve them, it is necessary to proceed, first of all, from the general principles of state regulation of industrial fishing in Russia, in the construction of which the existing economic relations in the field of industrial fishing are built.

When establishing the modern Russian system of Fishing Industry State Management, the so-called "historical principle" of granting the right to use aquatic biological resources was defined as the basis for its development, which is characteristic of the legislation of the most leading fishing countries. Their fishing is based on the exploitation of coastal and marine aquatic biological resources, which are characterized by significant scales and sizes of production.

In the Russian Federation, the historical principle is legally enshrined in Article 36 of Federal Act No. 52 of 24 April 24, 1995 "On the Animal World", according to which priority in providing the animal world for use in a particular territory or water area is given to Russian legal entities and citizens of the Russian Federation who previously carried out certain types of use of the animal world in this territory or water area and to land owners, landowners with appropriate funds and specialists.

This principle is connected with the need to preserve the objects of the animal world and their habitat, and its essence is to provide the subjects of nature management with a guarantee for the long-term and stable implementation of activities, as well as to ensure the continuity of rights to nature use. The reverse side of this principle is the artificial creation of a certain closeness of the fishing industry, which complicates the entry of new participants into the industry. However, with regard to marine fishing, this closeness does not particularly hinder its independent development, but rather contributes to the preservation of the potential and 
compliance with the environmental responsibility of nature users.

The historical principle in the field of fisheries is reflected mainly in the features of the distribution of quotas for the production (catch) of aquatic biological resources in marine and inland waters, established by Article 31 of Federal Act No. 166 of December 20, 2004 "On Fishing and the Conservation of Aquatic Biological Resources" (hereinafter - the Law on Fishing and the Conservation of Aquatic Biological Resources).

In accordance with parts 10 and 11 of Article 31 of the Act on Fisheries and Conservation of Aquatic Biological Resources, quotas for the extraction (Catch) of aquatic Bioresources in marine Waters, in Inland water bodies and international quotas granted to the Russian Federation are distributed in a proportionate ratio between persons whose contract on fixing the share of the quota for the extraction (catch) of aquatic bioresources expires by concluding a new contract with such persons on fixing the share of the quota for the extraction (catch) of aquatic bioresources for 15 years. The remaining quotas for the extraction (catch) of aquatic bioresources, for which industrial fishing and (or) coastal fishing were not previously carried out, or for aquatic bioresources in new areas of their extraction (catch), are distributed according to the results of auctions.

Thus, according to the basic principle of functioning, marine industrial fishing and industrial fishing in inland water bodies are practically equated.

Meanwhile, fishing in inland waters significantly differs in terms of production, seasonality, scale, methods of production and organization of fishing, equipment and technologies. In addition, fishing in inland waters is characterized by insignificant volumes of catch of aquatic bioresources and other socioeconomic significance. As a rule, this type of activity is occupied by small organizations that use seasonal labor with temporary employment, which, at the same time, are of significant socio-economic importance for the local population.

This circumstance also affects the peculiarities of the administrative regulation of fishing. For example, according to the Fishing Rules for the East Siberian Fishery Basin, approved by the order of the Ministry of Agriculture of the Russian Federation of June 26, 2020, No. 347. All legal entities and individual entrepreneurs in the implementation of fishing are required to submit to the territorial bodies of the Federal Agency for Fisheries information on the extraction (catch) of aquatic bioresources on the 5th, 10th, 15th, 20th, 25th and last day of each month no later than one day after the specified date (with the exception of fishing carried out on ships filing daily ship reports). At the same time, fishing in inland water bodies is carried out without the use of vessels that submit daily ship reports. When fishing in lake fishing areas in the Arctic zone of the Sakha Republic (Yakutia), there is no communication with the outside world during the entire season.

However, the main problem of the lack of a clear distinction between types of fishing and differences in approaches to the regulation of marine and inland fisheries is the unjustified economic isolation of the latter, which results in the inability to create the necessary conditions for attracting investment in the fishing industry of the Sakha Republic (Yakutia). Fishing organizations of the Republic that have the right to extract (catch) aquatic biological resources, which is actually the most important asset, today can not fully implement it and are not able to independently get out of this situation without external support.

This is due to the fact that, in accordance with article 32 of the Act on Fisheries and on the Conservation of Aquatic Biological Resources, the transfer of the right to extract (Catch) aquatic biological resources from one person to another person is allowed only in cases defined by this Federal Act, as well as in the order of universal succession in accordance with Civil Law. However, certain cases of transfer of rights are not currently provided for by this Act, so there is only one way to transfer the right, it is the reorganization of the legal entity that has this right. This implies that there are limited ways to realize the economic potential of the right to extract (catch) aquatic bioresources.

The inability to attract long-term project financing on acceptable terms and low financial returns from users of aquatic bioresources do not cover the Republic's budget investments in the industry. On the one hand, due to the cancellation of subsidies from the state budget of the Sakha Republic (Yakutia) for industrial fishing to fishing farms with industrial quotas of more than 50 tons, the volume of fish harvesting in the Republic has decreased more than twofold (from 3,225.7 tons in 2016 to 1,271. 2 tons in 2019). On the other hand, the possibilities of the state budget are strictly limited and cannot serve as a donor as the only basis for the existence of the fisheries industry.

Thus, one of the most important tasks of the sustainable development of industrial fishing in the Sakha Republic (Yakutia) today is the creation of favorable conditions for attracting investment.

The crisis in the activities of organizations of the fisheries industry poses a threat to the sustainable development of the Arctic zone of the Sakha Republic (Yakutia), primarily, this concerns the Bulunsky, Allaikhovsky, Nizhnekolymsky, Ust-Yansky uluses of the Sakha Republic (Yakutia), whose population directly depends on the activities of organizations in this industry.

On the way to overcome this problem, the most promising solution is to soften the legal regime for the use of aquatic biological resources by expanding the methods provided for by law for transferring the right to extract (catch) aquatic biological resources from one person to another, provided for in article 32 of the Law on Fisheries and Conservation of Aquatic Biological Resources.

Since we are talking about the right to use natural resources that are in state ownership, we should consider expanding the methods of transferring the right to extract (catch) aquatic bioresources by analogy with the provisions on the transfer of the right to use subsurface areas and the reissue of licenses for the use of subsurface areas, established by Article 17.1 of the Law of the 
Russian Federation of February 21, 1992 No. 2395-I "On Subsurface Resources", which, in addition to the transfer of the right to use in the order of universal succession, also allows the following methods:

1) when a legal entity-a user of subsurface resources acts as the founder of a new legal entity established to continue operations on the provided subsurface area in accordance with the license for the use of the subsurface area, subject to the conditions specified by law;

2) when transferring the right to use a subsurface area by a legal entity - a subsurface user who is the main company, to a legal entity that is its subsidiary, or when transferring the right to use a subsurface area by a legal entity-a subsurface user who is a subsidiary, to a legal entity that is its main company, subject to the conditions specified by law;

3) when a business entity acquires, in accordance with the procedure provided for by Federal Law No. 127-FZ of October 26, 2002 "On Insolvency (Bankruptcy)", the property (property complex) of a bankrupt enterprise (a subsurface user), subject to the conditions specified by law.

These methods of transferring the right of use do not contradict the general logic of natural resource law of the Russian Federation and the principles of rational nature management, since they do not exclude compliance with all the requirements and conditions for the implementation of the licensed type of activity to the new owner of the right.

The solution of this problem opens up new opportunities for the development of the fisheries industry and will ensure an increase in the economic value of aquatic biological resources in accordance with the opportunities and needs of the market. This will allow, for example, fishing organizations to cooperate with each other and other investors not only by reorganizing the legal entity, which implies benefits for one of the parties, to create joint subsidiaries with the preservation of management and the right to receive a share of income, as well as to use the new opportunities provided by Federal Act No. 193 of July 13, 2020 "On State Support for Business Activities in the Arctic Zone of the Russian Federation". In the current situation, the limits of the provision of state support measures provided for by this law for business activities in the Arctic zone of the Russian Federation are very limited, since, as a general rule, the types of business activities that a candidate for Arctic residency plans to carry out must be new to him, not previously carried out. Thus, existing fishing enterprises cannot apply for the status of a resident of the Arctic zone of the Russian Federation. However, if the Law on Fisheries and Conservation of Aquatic Biological Resources provides for the possibility of transferring the right to use aquatic biological resources to subsidiaries or parent organizations, the latter will already be able to apply for the benefits and preferences provided for Arctic residents.
The supply of fish in freshwater has a set of features related to the seasonality of fishing, the dynamics of aquatic bioresources, the complexity of predicting stocks of aquatic bioresources and determining the rational share of their withdrawal without compromising reproduction in natural conditions. Of course, the sustainable development of industrial fisheries should primarily be based on reducing the anthropogenic load on the ecological system to the maximum permissible level. At the same time, the management should be focused on the rationalization of fishing to increase profits per unit of production assets used, as well as on attracting highly qualified specialists to fishing, that is, increasing the investment attractiveness of this industry. With this approach, inland fisheries can contribute substantially to increased food security, poverty alleviation, livelihoods, human well-being and ecosystem function. A robust fishery cannot function sustainably against the background of inflexible and limited solutions.

\section{References}

1. FAO. The State of World Fisheries and Aquaculture 2020. Sustainability in action. Rome. (2020) Retrieved from: $\underline{\text { http://www.fao.org/publications/card/en/c/CA9229E }}$ $\underline{\mathrm{N}}$

2. V.A. Fedorova International journal of applied and fundamental research 5-3, 478-482 (2015)

3. Stecyuk V.V. Customs Policy of Russia in the Far East 2(87), 65-76. 2019

4. Law of the Russian Federation № 2395-I "On Mineral Resources" (1992)

5. Federal Law № 52 "On the Animal World" (1995)

6. Federal Law№ 166 "On Fisheries and Conservation of Aquatic Biological Resources" (2004)

7. Federal Law № 93 "On State Support for Business Activities in the Arctic Zone of the Russian Federation" (2020)

8. Federal Law№ 127 "On Insolvency (Bankruptcy)" (2002)

9. Order of the Ministry of Agriculture of the Russian Federation № 347 "On Approval of the Fishing Rules for the East Siberian Fisheries Basin" (2020)

10. D. Islam, F. Berkes. Maritime Studies 15, 1 (2016).

11. S. Ksenofontov, N. Backhaus \& G. Schaepman-Strub Polar Record, 53(3), 289-303 (2017)

12. S.J. Cooke, E.H. Allison, T. Douglas Beard, R. Arlinghaus, A.H. Arthington, D.M. Bartley, I.G. Cowx, C. Fuentevilla, N. Leonard, K. Lorenzen, A.J. Lynch, V.M. Nguyen, S.-J. Youn, W.W. Taylor, R.L. Ambio, 7 (2016)

\section{Conclusion}

